\title{
The NASA-Goddard Multi-scale Modeling Framework-Land Information System: Global land/atmosphere interaction with resolved convection ${ }^{\text {th }}$
}

\author{
Karen I. Mohr ${ }^{\mathrm{a}, *}$, Wei-Kuo Tao ${ }^{\mathrm{a}}$, Jiun-Dar Chern ${ }^{\mathrm{a}, \mathrm{b}}$, Sujay V. Kumar ${ }^{\mathrm{a}, \mathrm{c}}$, Christa D. Peters-Lidard ${ }^{\mathrm{a}}$ \\ ${ }^{a}$ NASA-Goddard Space Flight Center, Greenbelt, MD 20771, USA \\ ${ }^{\mathrm{b}}$ Goddard Earth Sciences Technology and Research, Morgan State University, Baltimore, MD 21251, USA \\ ' Science Applications International Corp., McLean, VA 22102, USA
}

\section{A R T I C L E I N F O}

\section{Article history:}

Received 5 May 2011

Received in revised form

8 February 2012

Accepted 28 February 2012

Available online 10 May 2012

\section{Keywords:}

Land-atmosphere interaction

Earth system modeling

Global modeling

Atmospheric prediction

Hydrologic prediction

\begin{abstract}
A B S T R A C T
The present generation of general circulation models (GCM) use parameterized cumulus schemes and run at hydrostatic grid resolutions. To improve the representation of cloud-scale moist processes and land-atmosphere interactions, a global, Multi-scale Modeling Framework (MMF) coupled to the Land Information System (LIS) has been developed at NASA-Goddard Space Flight Center. The MMF-LIS has three components, a finite-volume (fv) GCM (Goddard Earth Observing System Ver. 4, GEOS-4), a 2D cloud-resolving model (Goddard Cumulus Ensemble, GCE), and the LIS, representing the large-scale atmospheric circulation, cloud processes, and land surface processes, respectively. The non-hydrostatic GCE model replaces the single-column cumulus parameterization of fvGCM. The model grid is composed of an array of fvGCM gridcells each with a series of embedded GCE models. A horizontal coupling strategy, GCE $\leftrightarrow$ fvGCM $\leftrightarrow$ Coupler $\leftrightarrow$ LIS, offered significant computational efficiency, with the scalability and I/O capabilities of LIS permitting land-atmosphere interactions at cloud-scale. Global simulations of 2007-2008 and comparisons to observations and reanalysis products were conducted. Using two different versions of the same land surface model but the same initial conditions, divergence in regional, synoptic-scale surface pressure patterns emerged within two weeks. The sensitivity of largescale circulations to land surface model physics revealed significant functional value to using a scalable, multi-model land surface modeling system in global weather and climate prediction.
\end{abstract}

Published by Elsevier Ltd.

\section{Introduction}

The land and atmosphere form a highly coupled system. Surface heat and momentum fluxes are linked to the surface net radiation flux, the vegetation state, and the profiles of temperature and water from below the surface up through the atmospheric boundary layer. The fluxes of heat, momentum, and moisture across the land/ atmosphere interface are influenced by the heterogeneous character of the land surface layer and vary on spatial scales ranging from meters to thousands of kilometers. Linking the water and energy cycles is precipitation. Feedbacks between the heterogeneous land surface and the boundary layer affect the development of clouds and precipitation (review in Pielke, 2001). The vertical distribution of latent heat released through the formation of clouds

\footnotetext{
is Thematic Issue on the Future of Integrated Modeling Science and Technology. * Corresponding author. Mesoscale Atmospheric Processes Laboratory, Code 612, NASA-Goddard Space Flight Center, Greenbelt, MD 20771, USA. Tel.: +1301614 6360; fax: +13016145492.

E-mail address: karen.mohr-1@nasa.gov (K.I. Mohr).
}

and precipitation modulates the large-scale atmospheric dynamics of the low and mid-latitudes, affecting the distribution, intensity, and longevity of waves, jets, and fronts, and thus to future precipitation patterns. Coupling a general circulation model (GCM) to a land surface model (LSM) allows for two-way interaction of atmospheric moist processes with the land surface. By coupling a GCM to a multi-model Land Information System (LIS) rather than to a single LSM, significant additional physical and functional flexibility is achieved (Kumar et al., 2006; Peters-Lidard et al., 2007). This paper describes the NASA-Goddard finite-volume Multi-scale Modeling Framework-Land Information System (MMF-LIS), a global model framework capable of explicitly resolving cumulus convection and simulating cloud-scale land/ atmosphere interactions. The MMF-LIS integrates an atmospheric GCM with a 2D cloud-resolving model (CRM) for explicit simulation of cumulus clouds and couples the LIS to the GCM. We describe the development and operation of the current Goddard MMF-LIS, focusing on the model coupling and its initial testing, particularly with respect to surface variables. This paper can be viewed as a third companion to two previous papers on LIS, the first 
description of LIS by Kumar et al. (2006) and the role of LIS in coupled mesoscale modeling by Kumar et al. (2008). The MMF-LIS enhances our ability to investigate the integrated impact of small-scale cloud microphysics and soil and vegetation states on regional to global-scale circulations, cloud patterns, and precipitation.

\section{Background: global multi-scale modeling}

The current generation of GCMs used in operational global weather and short-term climate forecasting by the National Centers for Environmental Prediction (NCEP), the European Centre for Medium-Range Weather Forecasts (ECMWF), and the NASA Global Modeling and Assimilation Office have fully interactive land/ atmosphere coupling using single LSMs, respectively, Noah (Ek et al., 2003), Hydrology-Tiled ECMWF Scheme for Surface Exchanges over Land (H-TESSEL, Balsamo et al., 2009), and Catchment (Koster et al., 2000). Although the NCEP Global Forecast System (GFS) uses the NASA LIS for land data assimilation, only Noah is fully and directly coupled to the GFS atmospheric model component (Saha et al., 2010). These operational LSMs use tiles or catchment sub-divisions to improve the representation of the land surface heterogeneity within GCM gridcells. However, the surface fluxes generated are spatially averaged so that the atmospheric component can use a parameterized cumulus scheme to determine gridcell clouds and precipitation. Model comparison projects in the Global Energy and Water Cycle Experiment (GEWEX) have shown that simulations of various types of clouds and cloud systems from different geographic locations by cloud-resolving models (CRM) agree with observations better than those from cumulus parameterizations used by the current generation of GCMs (Moncrieff et al., 1997; Randall et al., 2003b). The lumping of land/atmospheric interactions and the use of cumulus parameterizations for cloudscale moist processes are sources of significant uncertainty in predictions at larger scales (Zhang et al., 2005; Pauluis and Garner, 2006; Shutts and Palmer, 2007).

The grid size of GCMs is moving toward grids sufficiently fine to explicitly resolve many cloud systems, but the computational cost is enormous and, because of the importance of unresolved processes at still finer scales, convergence is by no means assured. A CRM can simulate clouds at meter- to kilometer-scale grid resolutions. Computational infrastructure typically limits the simulation of clouds and cloud systems by CRMs to a relatively small domain $\left(\leq 10^{3}-\mathrm{km} \times 10^{3}-\mathrm{km}\right)$ and short time periods ( $<1$ month). Grabowski (2001) and Khairoutdinov and Randall (2001) first proposed the use of 2D cloud-resolving models as a "superparameterization" to simulate cloud processes within GCM gridcells, replacing cumulus parameterizations. Arakawa (2004) describes this configuration as a multi-scale modeling framework (MMF). In the MMF, a non-hydrostatic 2D CRM takes the place of the single-column cumulus parameterization used in conventional GCMs (Randall et al., 2003a; Arakawa, 2004; Tao et al., 2009).

There are two teams developing MMFs, a newer effort by Goddard and a longer running effort by Colorado State University (CSU). The CSU MMF combines the Community Atmosphere Model 3.0 (CAM, Collins et al., 2006), the System for Atmospheric Modeling (SAM, Khairoutdinov and Randall, 2003), and the Community Land Model (CLM, Dai et al., 2003) to form the super-parameterized CAM (SP-CAM). The GCMs at the core of the Goddard and CSU MMFs share a common ancestor, the National Center for Atmospheric Research (NCAR) Community Climate Model Ver. 3 (CCM3), but underwent separate additional development by Goddard and NCAR researchers.

Taking on phenomena that have been identified as difficult for GCMs to reproduce well, CSU researchers have shown better results with SP-CAM in reproducing the diurnal cycle of convection (DeMott et al., 2007), orogenic propagating cloud systems (Pritchard et al., 2011), subtropical low cloud fields (Blossey et al., 2009), and precipitation anomalies associated with the Madden-Julian oscillation (Benedict and Randall, 2009) and El Niño-Southern Oscillation (ENSO, Khairoutdinov et al., 2008). Tao et al. (2009) compare the SP-CAM and an earlier version of the Goddard MMF. Both MMFs resulted in better representation of global energy and water cycles compared to GCMs with cumulus parameterizations but had their own set of biases from using 2D CRMs and prescribed sea surface temperatures. Researchers at Pacific Northwest National Laboratory (PNNL) added to SP-CAM an explicit-cloud parameterized-pollutant approach that links aerosol and chemical processes on the large-scale grid with statistics of cloud properties and processes resolved by the CRM (Wang et al., 2011a, 2011b). The PNNL MMF can be used to study aerosol effects on cloud microphysics (indirect effect) globally, a study topic typically confined to a CRM-sized domain.

In Tao et al. (2009), the differences between the CSU and Goddard MMFs were smaller than their differences with standard GCMs. These differences may become larger less from the diverging evolution of their parent GCMs than from the addition of additional model components. The emphasis here at Goddard on land/atmosphere interactions and hydrologic model development has produced an MMF in which "multi-scale" includes the land surface and a significant range of options are available to the user through LIS. Here, we describe the development and operation of the current Goddard MMF-LIS, focusing on the model coupling and its initial testing, particularly with respect to surface variables.

\section{Components of MMF-LIS}

Fig. 1 depicts the integration and coupling of the components of MMF-LIS. The three principal components are a finite-volume ( $\mathrm{fv}$ ) GCM (Goddard Earth Observing System Ver. 4, GEOS-4), a 2D CRM (Goddard Cumulus Ensemble, GCE), and the LIS, representing the large-scale atmospheric circulation, cloud processes, and land surface processes, respectively. All numerical analysis is written in FORTRAN90. The $C$ language is used to expand object-oriented features already in FORTRAN90, providing a virtual objectoriented programming environment managing operations within and between components. The MMF-LIS components represent the work of several different teams of scientists and engineers at Goddard. The fvGCM was developed in the former NASA Data Assimilation Office. The successor to the Data Assimilation Office, the Global Modeling and Assimilation Office (GMAO), adopted the fvGCM as their first operational model. The CRM was developed in the Mesoscale Atmospheric Processes Laboratory, and the LIS was developed by the Hydrological Sciences Laboratory. Assisted by the Hydrological Sciences Laboratory, the Mesoscale Atmospheric Processes Laboratory performed the integration and coupling of the three MMF-LIS components.

\subsection{The Goddard Earth Observing System Ver. 4 (GEOS-4)}

The fvGCM of MMF-LIS, the GEOS-4, was constructed by combining the finite-volume dynamical core developed at Goddard (Lin, 2004) with the physics package of the NCAR CCM3, which represents a well-balanced set of processes with a long history of development and documentation (Kiehl et al., 1998). The unique features of the finite-volume dynamical core include an accurate conservative flux-form semi-Lagrangian transport algorithm with a monotonicity constraint on sub-grid distributions that is free of Gibbs oscillation (Lin and Rood, 1996, 1997), a terrain-following Lagrangian control-volume vertical coordinate ( $\sigma$-coordinate), 


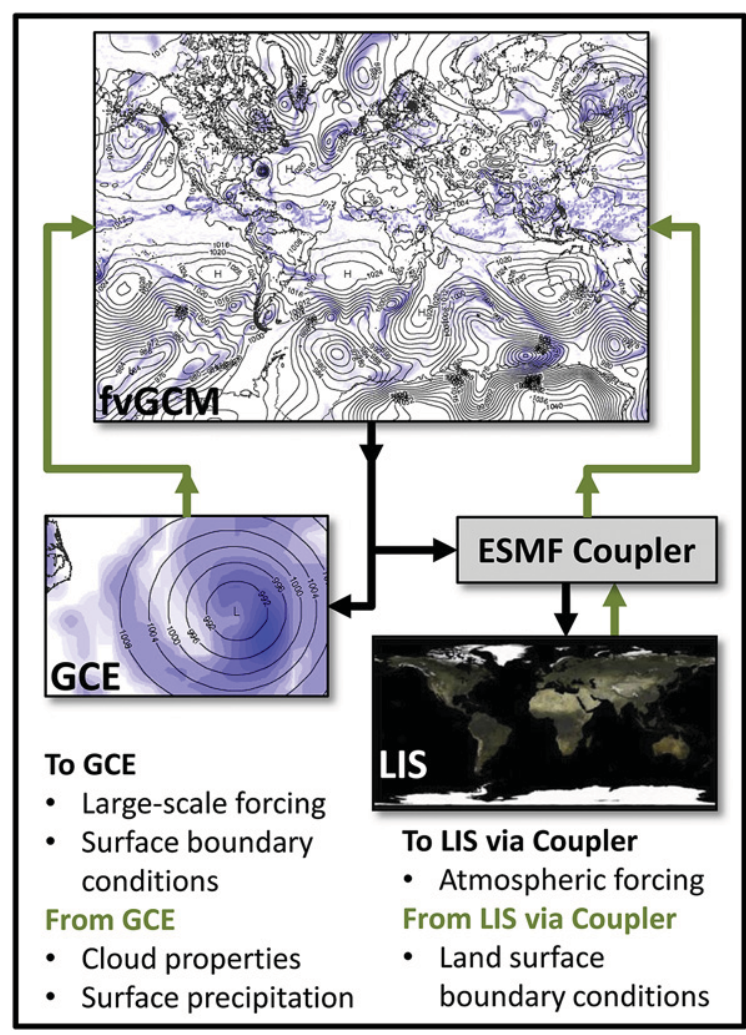

Fig. 1. Integration and coupling of MMF-LIS. Black arrows depict the flow of forcing input from the fvGCM to GCE and LIS, and green arrows depict the flow of output from GCE and LIS to the fvGCM. Table 1 lists the specific input forcing variables to GCE and LIS. In the top and bottom left example maps, global daily pressure fields (hPa, black contours) and daily surface precipitation ( $\mathrm{mm}$, purple shading) are depicted. Global land cover is depicted in the bottom right map.

a physically consistent integration of the pressure gradient force for a terrain-following coordinate (Lin and Rood, 1997; Lin, 1998), and a mass-, momentum-, and total-energy-conserving vertical remapping algorithm.

Depending upon the application, the number of levels used in GEOS- 4 varies between 32 and 64, while the horizontal grid spacing can vary between $2.5^{\circ}$ and $0.125^{\circ}$. The GEOS- 4 and its successor, the GEOS-5, have been applied in climate simulation, data assimilation, and weather prediction modes. Atlas et al. (2005, 2007) and Shen et al. (2006a,b, 2010) tested their capability to simulate Atlantic hurricanes, adequately resolving problems like erratic track, abrupt re-curvature, intense extratropical transition, multiple landfall and re-intensification, and interaction among vortices.

\subsection{The Goddard Cumulus Ensemble (GCE)}

The GCE model has the longest history of the MMF-LIS components. It has been developed and refined at Goddard over two and a half decades for simulating convective clouds and cloud systems. The initial development and core features of the GCE model are in Tao and Simpson (1993), with reviews of the application of the GCE model to understanding precipitation processes in Tao (2003) and Tao et al. (2003). The GCE is a non-hydrostatic, anelastic CRM composed of prognostic equations for momentum, potential temperature, and water vapor mixing ratio. It includes solar and infrared radiative transfer processes, a Kessler-type two-category (cloud drops and rain) liquid water scheme, and a three-category (cloud ice, snow, and graupel/hail) bulk ice microphysics scheme. The GCE model's default bulk microphysical scheme has been modified to improve graupel concentrations in the stratiform region and cloud ice concentrations in the upper troposphere (Lang et al., 2007, 2011). These changes better address saturation issues in these regions and result in more realistic column ice water contents for longer-term simulations (Zeng et al., 2008, 2009).

\subsection{The Land Information System (LIS)}

The LIS is a scalable land data assimilation system that integrates a suite of advanced LSMs, high resolution satellite and observational data, data assimilation and parameter optimization techniques, and high-performance computing tools. The initial development and principal features of LIS are described in Kumar et al. (2006) and Peters-Lidard et al. (2007). The LIS infrastructure has three layers, 1) a core that controls the program execution and $\mathrm{I} / \mathrm{O}$ and manages the user-defined components; 2) a middle abstractions layer consisting of generic representations of LSMs, domains, land surface parameters, and running mode; 3 ) an extension of the abstractions layer for the user-selected LSM, domain, parameter set, and running mode. Executing LIS generates spatially and temporally distributed estimates of land surface processes using either observed or modelderived meteorology to constrain and force the user-specified LSMs. These models include the operational LSMs: CLM, Noah, and Catchment. In addition to new LSMs, multiple versions of the same LSM may be added and used within LIS. These features facilitate ensemble modeling studies and the benchmarking and sensitivity testing of new parameterizations and coupled modeling system configurations. The data assimilation functions of LIS are not currently used in MMF-LIS. Planned future upgrades will add data assimilation to the fvGCM, allowing future users to utilize the assimilation functions already in LIS.

The three available running modes in LIS, analysis, forecast, and coupled, are described in Kumar et al. (2006, 2008). Initially, the coupled running mode was designed for local- to regional-scale modeling. Input land cover datasets masked out areas containing inland water bodies, wetlands, and glaciers, and parameterizations for evaporation from these surfaces were by-passed. During MMF-LIS development, these parameterizations were re-integrated, and a global input dataset with these land covers was created.

\section{Coupling and execution of MMF-LIS}

\subsection{The atmosphere, fvGCM and GCE}

In Fig. 2, the atmosphere consists of an array of GCM gridcells each with a series of embedded 2D GCE models, representing a series of $x-z$ slices of the atmosphere. The size of the GCM gridcells, the number of embedded GCE models per gridcell, and the number of GCE internal gridcells are user-specified. Initialization, execution, and finalization of GCE operations are controlled by the fvGCM. An internal state variable (ISV) data structure is used to pass forcing and output variables such as temperature and humidity to and from the MMF-LIS components. The ISV has 5 degrees of freedom: 2 absolute spatial coordinates, latitude and longitude, and three relative spatial coordinates. For GCE, the latitude and longitude are the central geographical location of each fvGCM gridcell, and three Cartesian coordinates $(x, y, z)$ designate the relative position of GCE internal gridcells. The ISV makes it possible to preserve both grid geographical and processor layout seamlessly.

The passing of forcing ISVs from fvGCM to GCE initiates GCE execution. The atmospheric forcing variables passed to GCE such as temperature, humidity, and ozone are fvGCM-gridcell layer means, e.g., $\bar{T}$ (lon, lat, $0,0, \sigma)$. A coordinate transformation from the 


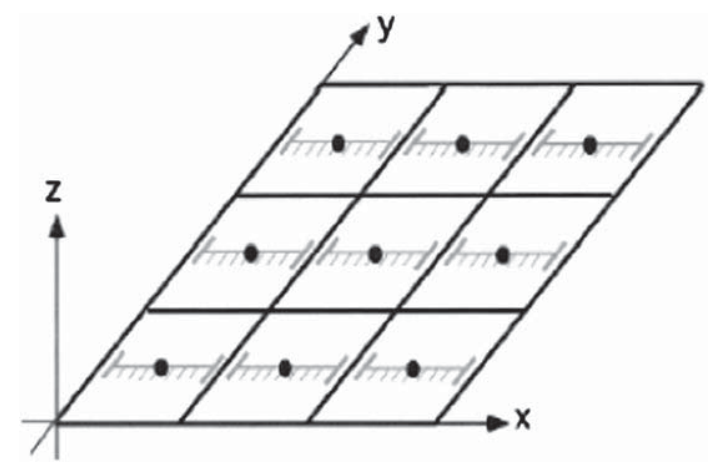

Fig. 2. The black squares are an array of GCM gridcells and the red lines inside them are embedded 2D time-variant CRMs. For comparison, the black dots represent 1D time-invariant cumulus parameterizations within a traditional GCM. Figure adapted from Tao et al. (2009).

terrain-following fvGCM $\sigma$-coordinate system to the fixed GCE Cartesian coordinate system completes the transfer from the fvGCM to GCE. For land surface fluxes, there are two options, 1) an fvGCM-gridell mean that is then randomized across the GCE internal grid to approximate surface turbulence, 2) the perturbation occurring at each GCE internal gridcell, e.g., $H^{\prime}$ (lon, lat, $\left.x, 0,0\right)$.

During GCE execution, GCE mean layer temperature, humidity, and cloud properties such as cloud ice mixing ratio are calculated for each member of the GCE array from its internal perturbations. After execution of the GCE array, temporal averaging takes place to account for the fvGCM clock time elapsed during execution of the GCE array. The temperature and humidity tendencies for the fvGCM gridcell \{e.g., $[\partial \bar{T}$ (lon, lat, $0,0, \sigma) / \partial t]_{\text {moist }}$ \} are calculated from the array of GCE layer means, a Cartesian to $\sigma$-coordinate transformation, and the elapsed clock time. These results are then passed back to the fvGCM. There are two options for subsequently forcing LIS, 1) the fvGCM-gridell means at the lowest fvGCM model layer, 2) temporally-averaged GCE internal perturbations at the lowest GCE model layer.

\subsection{The land-atmosphere coupling with LIS}

The coupling of the fvGCM to LIS is enabled by the NASA Earth System Modeling Framework (ESMF, Hill et al., 2004). The ESMF is open-source software to assist the development of highperformance, multi-component numerical earth system models. It offers a variety of data structures for transferring data between components, tools and utilities to ensure component interoperability with consistent component behavior, and libraries for regridding, time advancement, and other common modeling functions.The MMF-LIS coupling uses the ESMF Coupler Component (ESMF_CplComp), import and export state objects (ESMF_State), and the Time Manager utility (c.f., Collins et al., 2005; Balaji et al., 2011). The Coupler is used only for transferring data between the fvGCM and LIS, as ESMF components and utilities are designed for data transfer and re-gridding, not physical/dynamical computations. Because the original design of LIS wrapped the ESMF Coupler superstructure around LIS (Kumar et al., 2006), the Coupler did not have to be added, only modified to recognize the ISVs used in the atmospheric components as forcing/output data container variables that could be pointed to by the import/export ESMF state objects.

To initiate LIS execution, the Coupler takes in the import state object pointing to the ISVs of forcing data for LIS (Table 1) and maps the forcing data to the LIS grid. After LIS execution, any required temporal and spatial averaging takes place within LIS. An export state object then points to the output that will be mapped as fvGCM and GCE lower boundary conditions. The Time Manager accounts for the time elapsed during LIS operations. Because the MMF-LIS coupling is based on the template developed for coupling LIS to the mesoscale Weather Research and Forecasting (WRF) model, the sequence of interactions between fvGCM, the Coupler, and LIS is equivalent to the sequence for LIS-WRF diagrammed and described in Kumar et al. (2008).

The first attempt to add two-way land surface processes to MMF involved coupling a single LSM, CLM 2.1, to fvGCM, in a horizontal structure, GCE $\leftrightarrow$ fvGCM $\leftrightarrow$ CLM. This was the MMF configuration used in Tao et al. (2009). Although CLM permits up to 7 surface types to be specified within its gridcells to approximate the underlying land surface heterogeneity, its limited I/O capabilities required spatial averaging such that both input forcing and output boundary conditions pass to and from fvGCM at fvGCM resolution, e.g., $\bar{H}$ (lon, lat, $0,0,0)$. The horizontal structure of the older MMF was adapted for MMF-LIS, swapping LIS and the ESMF Coupler for the single LSM, creating GCE $\leftrightarrow$ fvGCM $\leftrightarrow$ Coupler $\leftrightarrow$ LIS.

A second strategy was considered, a vertical structure, fvGCM $\leftrightarrow$ GCE $\leftrightarrow$ Coupler $\leftrightarrow$ LIS, in which there would be multiple GCE-LIS couples embedded within each fvGCM gridcell. The vertical structure would avoid the communication overhead of passing ISVs through fvGCM. However, it would complicate processor distribution in parallel computing operations and incur significant computational cost to start and stop many instances of LIS and organize the ISVs for the surface boundary conditions. In comparison, the horizontal strategy involves a single instance of LIS and a main LIS grid at the same resolution as fvGCM. For simulating higher resolution interaction between the atmosphere and the land surface, multiple surface types, "tiles", at $1-10^{1}-\mathrm{km}$, can be specified within the LIS gridcells and the I/O passed to and from the Coupler at tile resolution. The computational cost is several times greater to calculate and pass surface fluxes at cloud-scale $(<10-\mathrm{km})$ resolutions. Because most land surface processes are parameterized as 1D phenomena and LIS time steps are on the order of several minutes, the total computational cost of running one instance of LIS, even with cloudscale tiles, is nominal compared to executing the GCE arrays.

\section{First results: a comparison of different land surface model physics}

\subsection{Physics differences, CLM version 2.0 vs. 2.1}

A significant functional advantage of coupling to LIS over a single LSM is the suite of abstractions available in LIS that expands the user's

Table 1

List of forcing inputs to GCE (left column) and LIS (right column). The LIS forcing height is fixed at the lowest fvGCM model layer. The ozone and SST state variables are derived from NOAA weekly Reynolds Optimum Interpolation SST Analysis Ver. 2 (Reynolds et al., 2002) and an ozone product merging the NASA Upper Atmosphere Research Satellite (UARS) ozone measurements (Ziemke et al., 1998) and the Atmospheric Model Intercomparison Project 2 (AMIP2) ozone dataset (Kanamitsu et al., 2002), respectively.

\begin{tabular}{|c|c|}
\hline GCE forcing & LIS forcing \\
\hline Local solar time, $t$ (lat, lon) & Local solar time, $t$ (lat, lon) \\
\hline $\mathrm{O}_{3}$ (lat, lon, $z$ ), imposed & Winds, $u, v$ (lat, lon) \\
\hline SST(lat, lon), imposed & Rain and snow rate, $r$ (lat, lon) \\
\hline Temperature, $T$ (lat, lon, $z$ ) & Air temperature, $T_{\text {air }}$ (lat, lon) \\
\hline Humidity, $q$ (lat, lon, $z$ ) & Specific humidity, $q$ (lat, lon) \\
\hline Winds, $u$ (lat, lon, $z$ ), $v$ (lat, lon, $z$ ) & Sea level pressure, $P$ (lat, lon) \\
\hline $\begin{array}{l}\text { Advection (lat, lon) of } T \text { and } q \text {, } \\
\quad \operatorname{adv}(\bar{T}), \operatorname{adv}(\bar{q})\end{array}$ & Shortwave radiation, $\mathrm{SW}_{\mathrm{in}}$ (lat, lon) \\
\hline $\begin{array}{l}\text { Sensible and latent heat flux, } \\
H(\text { lat, lon), LE(lat, lon) }\end{array}$ & Longwave radiation, $\mathrm{LW}_{\text {in }}$ (lat,lon) \\
\hline
\end{tabular}


capability to test codes and compare simulations using an ensemble modeling approach with different LSMs and/or versions of those models. The testing of new models or new model physics in LIS is accomplished by the addition or removal of components in the third layer (the extension of abstractions layer) where codes for specific LSMs reside. If new LSMs are added, communication between the new model and lower layers is established using the templates for $\mathrm{I} / \mathrm{O}$ contained in the second layer. The LSMs added to LIS are no longer limited by their native $\mathrm{I} / \mathrm{O}$ and tiling capability as these functions are determined and controlled by the top-level core layer.

The original version of CLM in LIS was version 2.0. Added to LIS was the modified version of CLM, version 2.1, the same version of CLM directly coupled to MMF in the configuration of Tao et al. (2009). In CLM 2.1, there are several important changes to the model physics involving the computation of atmospheric forcing height, vegetation temperature, canopy interception of precipitation, and the drag coefficient between the underlying soil (or canopy surface) and the canopy air. All four of these state variables are used in determining the surface heat fluxes supplied to the atmospheric components. The underlying assumptions, the formulation of the equations for each variable, and the solution methods vary between versions. For example, the canopy interception in CLM 2.0 is calculated assuming a uniform precipitation rate over the gridcell compared to an assumption of a logarithmic probability distribution function for precipitation rates in CLM 2.1.

Because LIS had never before been run globally in coupled mode and new land covers and model physics were introduced, it was critical in the model development process to benchmark the
MMF-LIS against the MMF configuration of Tao et al. (2009). We ran and compared two simulations of MMF-LIS, one using CLM 2.0 and the other using CLM 2.1, to verify that MMF-LIS can produce physically realistic results and assess how changes to the physics of land surface processes would integrate over space and time to affect regional to global atmospheric circulations.

\subsection{Surface diagnostics}

The comparison of the different versions of CLM, original (2.0) versus modified (2.1), involved running MMF-LIS for two years, 2007-2008, using each version at horizontal resolutions of $2^{\circ} \times 2.5^{\circ}$ for fvGCM and 4-km for GCE, with time steps of 30-min (fvGCM), 10-s (GCE), and 3-min (LIS). Vertical resolutions were 30 layers (terrain-following) for fvGCM and 32 layers (fixed) for GCE. We specified the same simple surface heterogeneity as the MMF of Tao et al. (2009), 7 tiles per LIS gridcell and option 1 for land surface fluxes (fvGCM gridcell means). Because of the additional physical and computational complexity of cloud-scale heterogeneity, development of the MMF-LIS required that we first benchmark MMF-LIS against MMF using the same simple heterogeneity, leaving the testing of more complex representations of surface heterogeneity to future work.

Fig. 3 summarizes the annual daily mean 2-m air temperatures for CLM 2.0 (original, top panels), CLM 2.1 (modified, middle panels), and their difference (original-modified, bottom panels) for 2007 (left panels) and 2008 (right panels). In 2007, most of the differences between the original and modified versions of CLM are
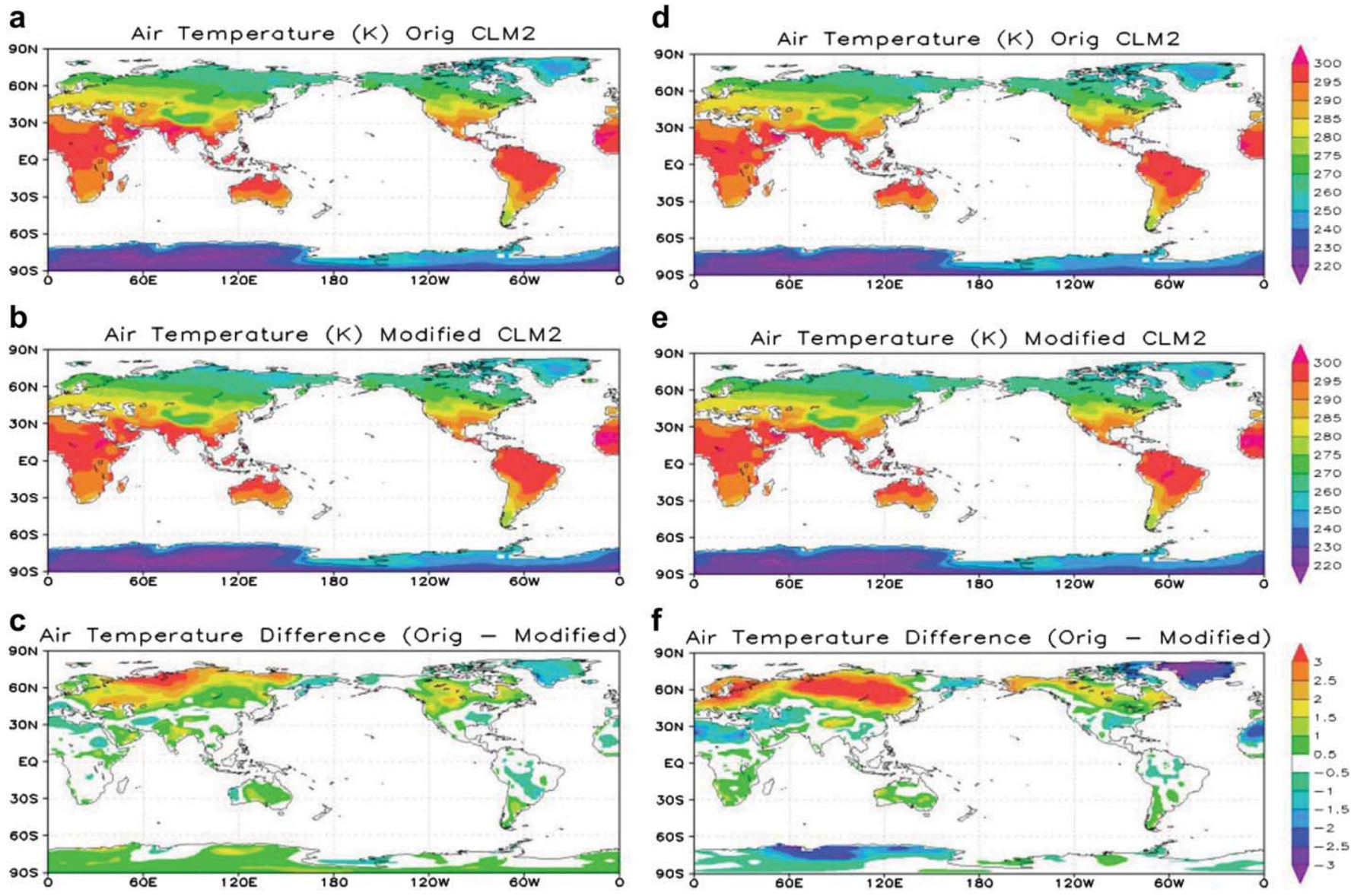

Fig. 3. Maps of the annual daily mean and difference 2-m air temperatures in Kelvins for CLM 2.0 and CLM 2.1 for 2007 (a-c) and 2008 (d-f) at the resolution of the fvGCM $\left(2^{\circ} \times 2.5^{\circ}\right)$. The top panels (a, d) are the original, CLM 2.0, results. The middle panels (b, e) are the modified, CLM 2.1, results. The bottom panels (c, f) are difference maps of CLM 2.0-CLM 2.1. The scales on the right column apply to the maps on the left column as well. 
positive, implying CLM 2.0 tended to produce warmer air temperatures than CLM 2.1. Differences greater than $1 \mathrm{~K}$ occur across much of Russia and Canada and in smaller areas of India, Australia, the Arabian Peninsula, and Antarctica. Noteworthy negative differences occur in Greenland, far-eastern Siberia, southern Brazil, and the North African coast. The trends in 2008 amplify the major trends of 2007, with a larger area of positive differences in Eurasia and Canada to Alaska and expanded areas of negative differences in Greenland and North Africa to the Middle East. Differences in Antarctica between $30^{\circ} \mathrm{E}$ and $150^{\circ} \mathrm{E}$ change sign from 2007 to 2008 as the pool of coldest air $(<220 \mathrm{~K})$ in CLM 2.1 in 2007 (panel b) is smaller in 2008 (panel e) versus CLM 2.0 (panels a and $d$, respectively). The positive differences in the northern middle to high latitudes are in vegetated areas, and negative differences in Greenland, North Africa, Antarctica, and far-eastern Siberia are in bare or ice covered areas.

Fig. 4 depicts the shortwave downward flux (SDF), typically the largest input to the surface energy budget. Because the first-order determinants of SDF are latitude, cloud fraction, and the optical thickness of clouds, the maps in Fig. 4 reflect zonal differences between the two versions in cloud cover and thus the radiation input to the surface energy budget. The areas of SDF less than $120 \mathrm{~W} \mathrm{~m}^{-2}$ over the northern high latitudes are noticeably larger in CLM 2.1 (panels b and e) than in CLM 2.0 (panels a and d). The differences between the two models (bottom panels) are proportionally much larger north and south of $30^{\circ}$, over $30 \%$ in Central Siberia, but only 10-15\% in Central America in 2007 (panel c).
During the daytime over vegetated surfaces, net radiation is dominated by the shortwave downward term.

The drag coefficient is important in determining how much SDF penetrates through the canopy and reaches the ground. Comparing the SDF in 2008 to the ground heat flux (Fig. 5a) indicates how much each version of CLM partitioned this energy into the fraction conducted into the surface versus the fraction available at the surface for evapotranspiration. The ground heat flux of the original CLM 2.0 tends to be greater in those areas with positive temperature differences in Fig. 3 and less in those areas with negative differences. Although on diurnal time scales, warmer surface temperatures due to enhanced ground heat flux feedback to the atmosphere through enhanced sensible heat flux. The enhanced sensible heat flux occurs only as long as it takes the surface layer air temperatures to adjust upward. The areas of positive and negative differences in Figs. 3 and 5 coincide such that the long-term mean sensible heat fluxes (not shown) in CLM 2.0 and 2.1 are similar in these regions. Because of the heat storage capacity of soil, ground heat fluxes and thus surface temperature (2008, Fig. 5b), both instantaneous and long-term means, may reflect significant memory of radiation inputs. For LSMs like CLM 2.0 that have a constant drag coefficient, Zeng et al. (2005) found that too much radiation was partitioned into the ground in areas with sparse canopies (e.g., Canadian and Siberian tundras) leading to warm surface temperature biases. The drag coefficient in CLM 2.1 is allowed to vary with the friction velocity and thus the canopy thickness, ameliorating this bias. a

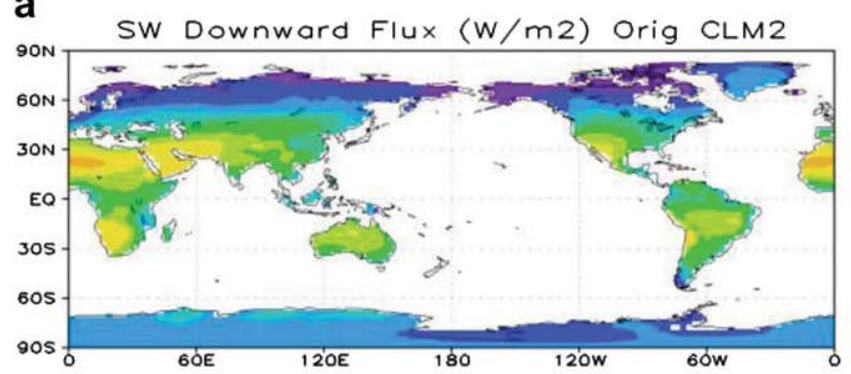

b
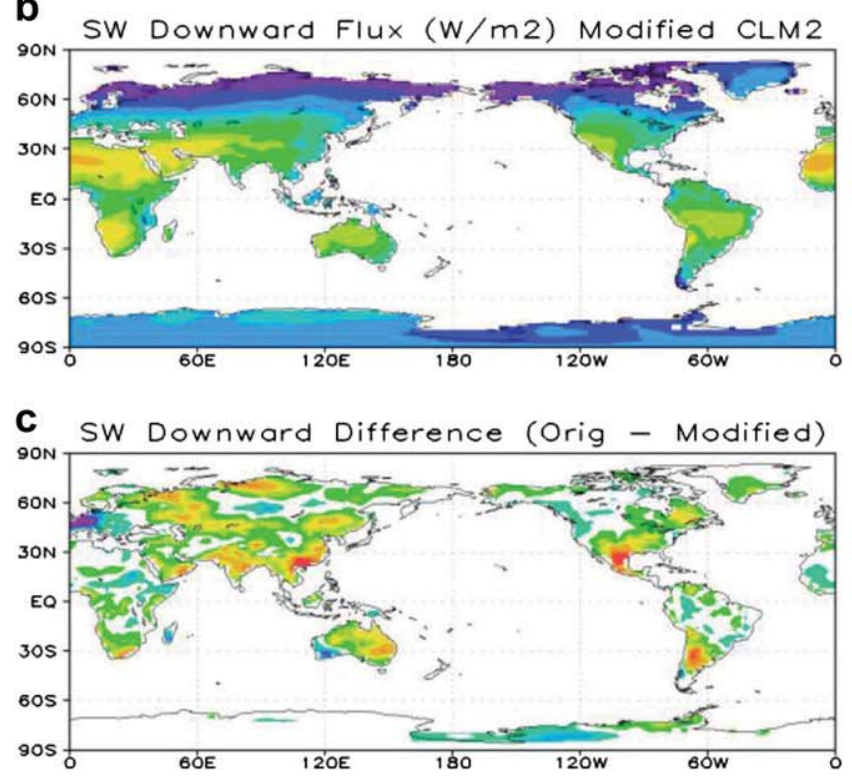

d
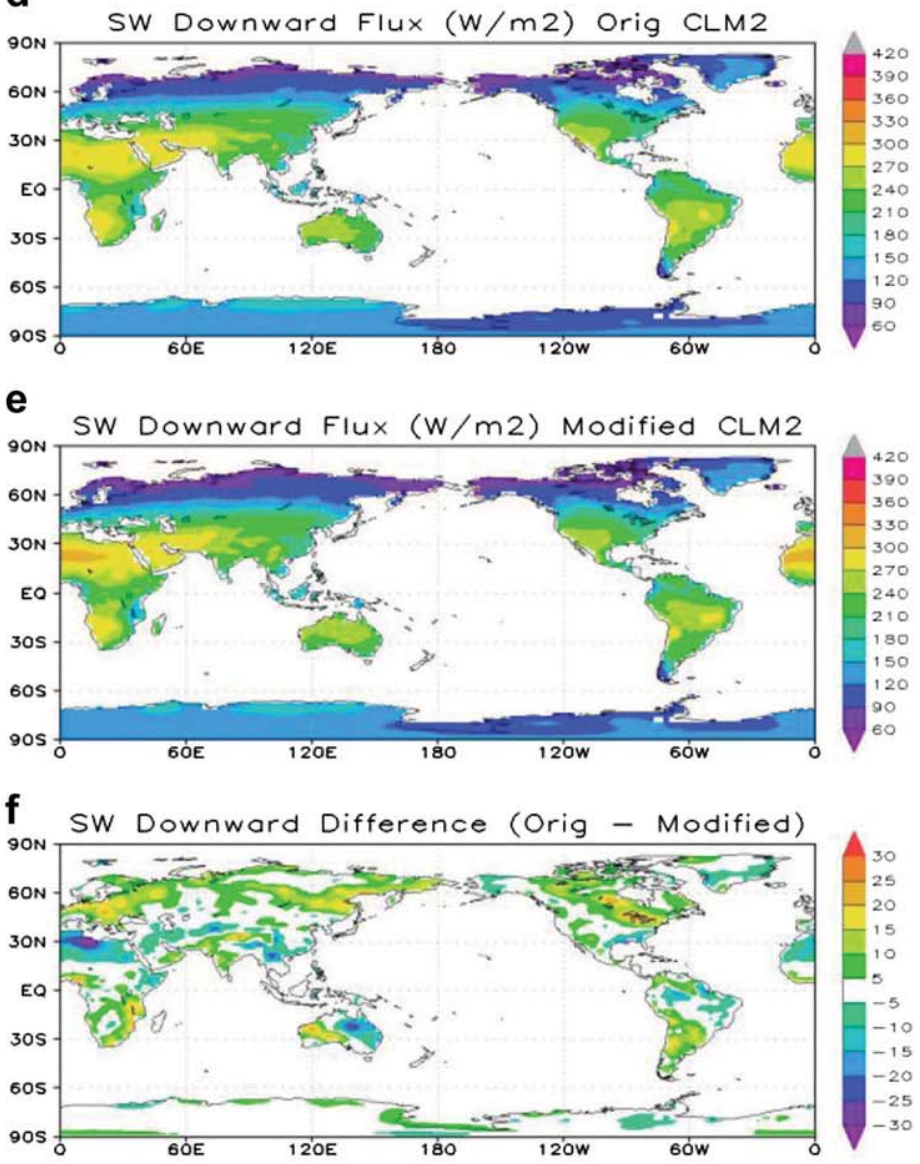

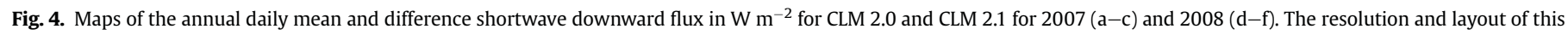
figure are the same as Fig. 3. 


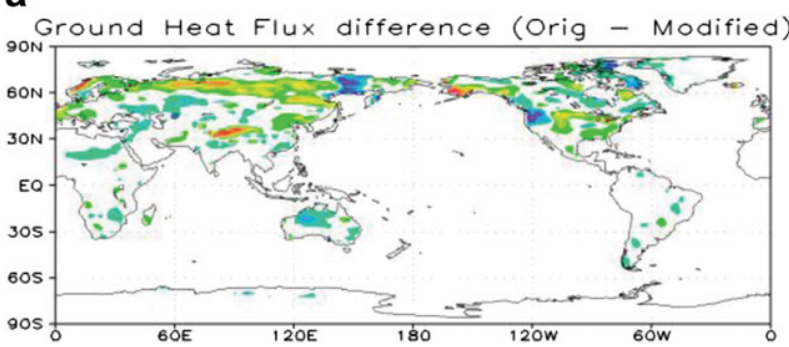

b

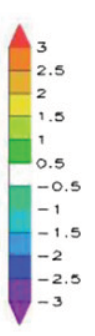

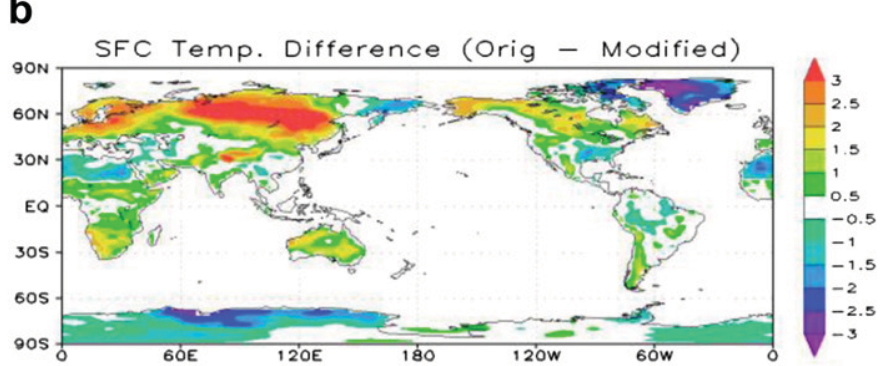

Fig. 5. The 2008 annual daily mean difference maps for a) ground heat flux in $\mathrm{W} \mathrm{m}^{-2}$ b) surface temperatures in Kelvins. For the sake of brevity, only maps for 2008 are shown.

\subsection{Effects on general circulation}

Fig. 4c depicts a large positive difference in SDF in Mexico in 2007. Fig. 6 contains time series of the gridcell centered at $26^{\circ} \mathrm{N} 102.5^{\circ} \mathrm{W}$ for the first month of the MMF-LIS simulations. Both simulations, CLM 2.0 and CLM 2.1, start with identical initial conditions. Differences between the two versions begin to emerge on 2 Jan. By 3 Jan, the difference in the daily maximum SDF is more than $300 \mathrm{~W} \mathrm{~m}^{-2}$ because the total cloud amount time series are at opposite ends of the $y$-axis. Although the SDF and cloud amount variability track each other closely, surface temperature variability in both versions tracks the variability in SDF/cloud amount closely only for the first two weeks. After two weeks, there is less variability in any of the variables in Fig. 6 and a smaller lag between changes in SDF/cloud amounts and changes in surface temperatures in the original CLM 2.0. Differences between the drag coefficients and vegetation temperatures in the models contribute to the rapidly evolving differences between the two versions in the surface variables of Fig. 6 .

The gridcell examined in this section is an important source region for dry, warm air that, if it penetrates the Central US, forms an elevated mixed-layer over humid airmasses transported from the Gulf of Mexico. Together, these two air streams have long been recognized for their impact on the convective weather environment in the Central US, particularly of the severe variety (Benjamin, 1986; Lakhtakia and Warner, 1987; Lanicci et al., 1987). Trier et al. (2011) demonstrate how differences in model predictions of surface conditions in the high terrain of Mexico can result in significant differences in warm season precipitation in the Central US. In Fig. 7, the map panels show how quickly the simulated US regional circulations diverge after initialization. Subtle differences between the two simulations appear by Day 5 at $200 \mathrm{mb}$ and Day 10 for the sea level pressures. By Day 15, there are substantial differences in the locations, orientations, and magnitudes of all cyclones/troughs and anticyclones/ridges in the region. After Day 16 in the critical Mexican gridcell (panels $d$ and h), the sea level pressure time series of the original CLM 2.0 simulation indicates a series of transitory anticyclones versus a persistent longwave trough in the modified CLM 2.1 simulation. The anticyclones contribute to and are strengthened by the surface heating indicated in Fig. 6 by the CLM 2.0 simulation. The differences in the regional pressure patterns due to feedbacks between surface conditions, cloud amounts, and the upper troposphere take approximately 10-14 days to emerge, consistent with the deterministic predictability limit of two weeks (reviews in Lewis, 2005; Yoden, 2007).

\section{Comparison to global gridded datasets}

\subsection{Surface fluxes}

The FLUXNET is a global network of more than 500 micrometeorological tower sites (Baldocchi et al., 2001). The siting of these towers in a wide variety of biomes has made it possible to create gridded flux products useful for model validation from local to global scales (Jung et al., 2009, 2010; Blyth et al., 2010; Schlosser and Gao, 2010). In addition to comparing the MMF-LIS results to

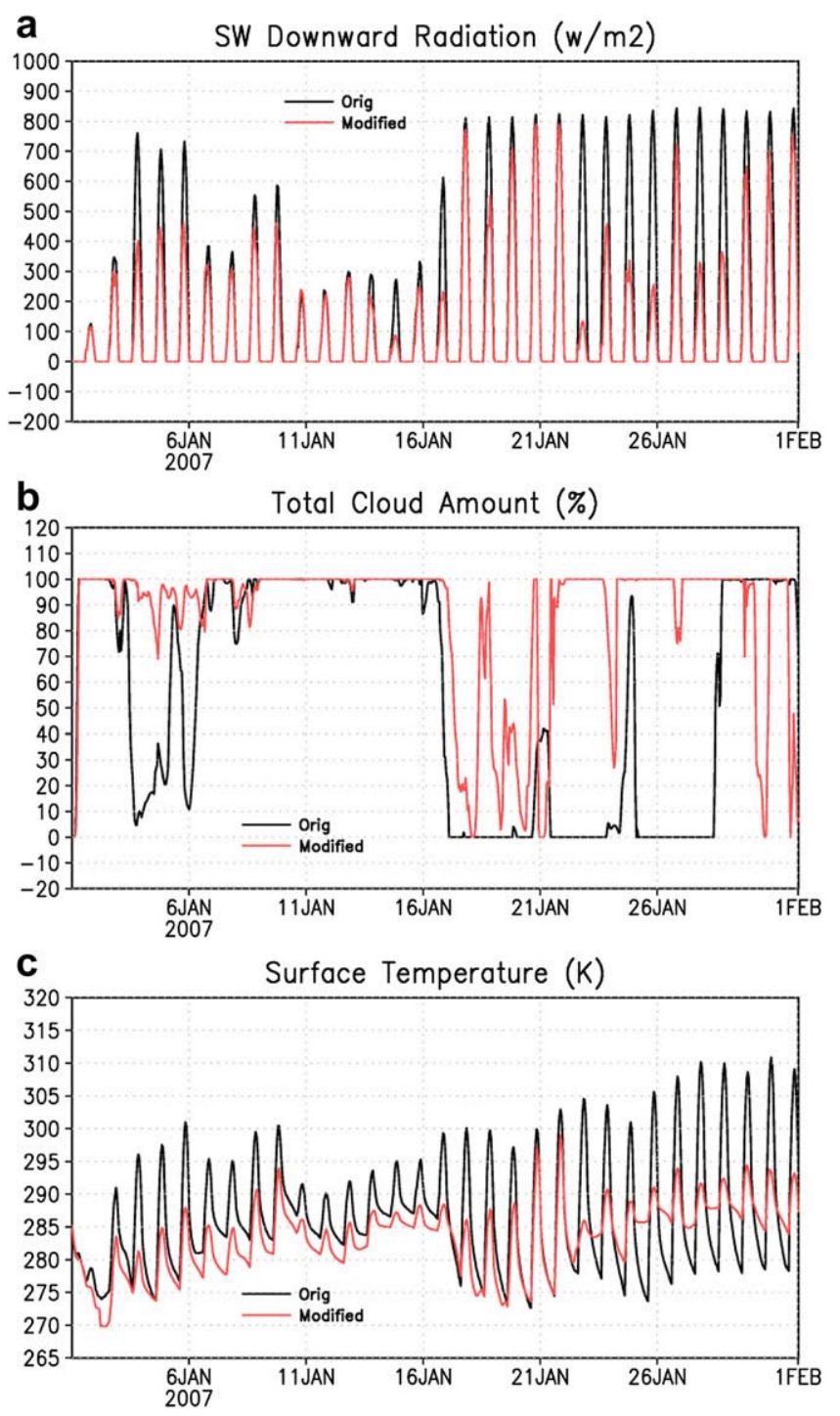

Fig. 6. Time series of the gridcell centered at $26^{\circ} \mathrm{N} 102.5^{\circ} \mathrm{W}$ (Mexico) for the firs month of the MMF-LIS simulations for a) shortwave downward radiation flux, b) total cloud amount, c) surface temperature. Both simulations, original CLM 2.0 (black line) and modified CLM 2.1 (red line), start with identical initial conditions. 


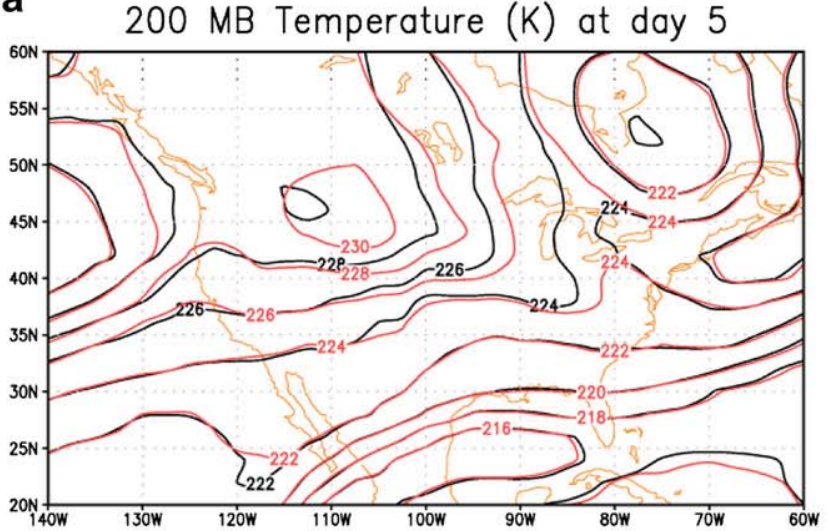

b $200 \mathrm{MB}$ Temperature (K) at day 10

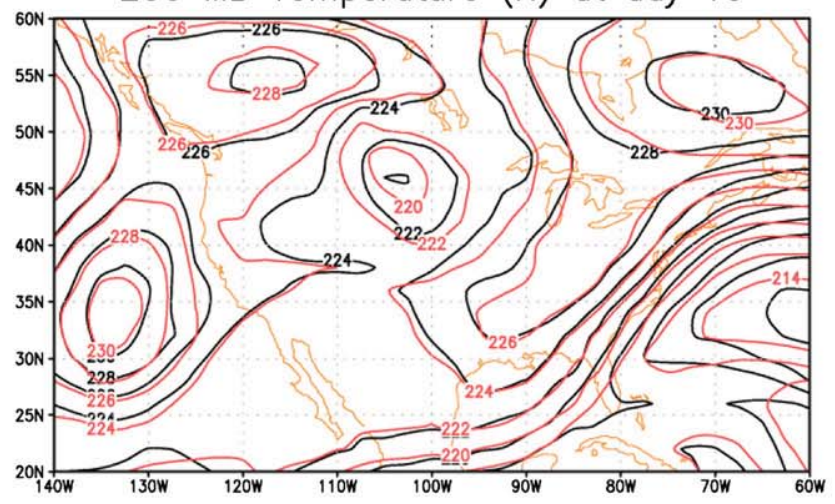

C $200 \mathrm{MB}$ Temperature (K) at day 15
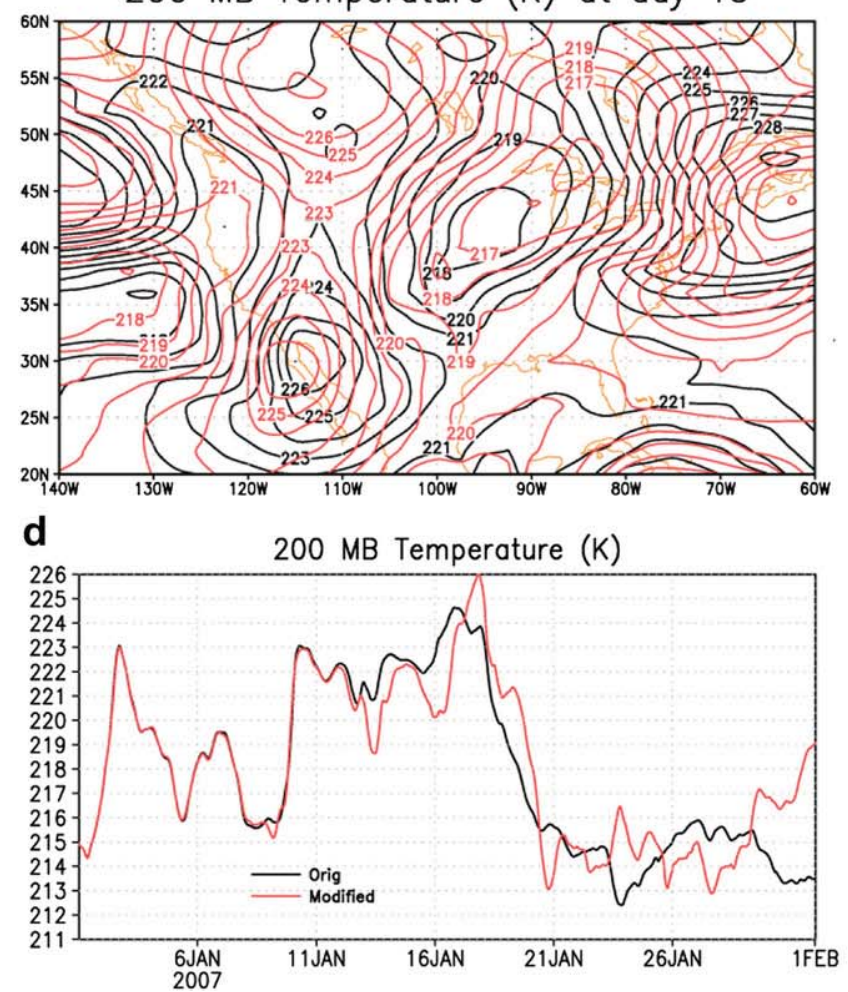

e

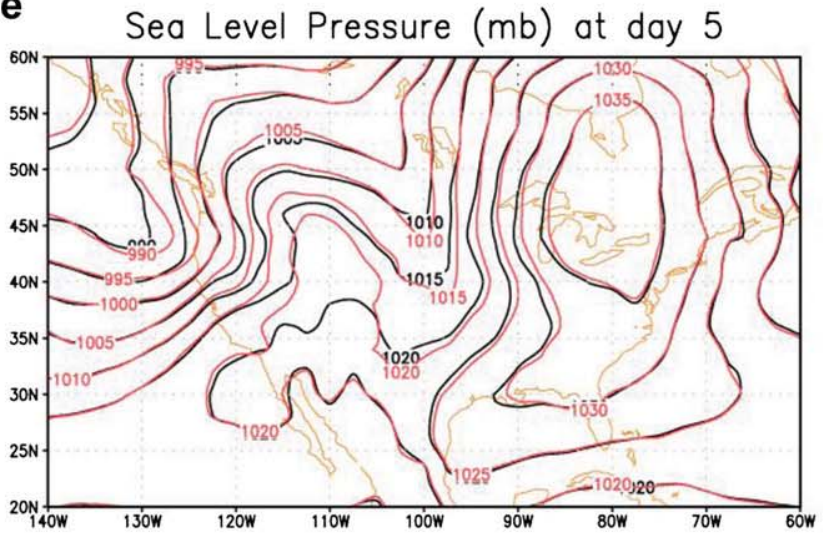

f
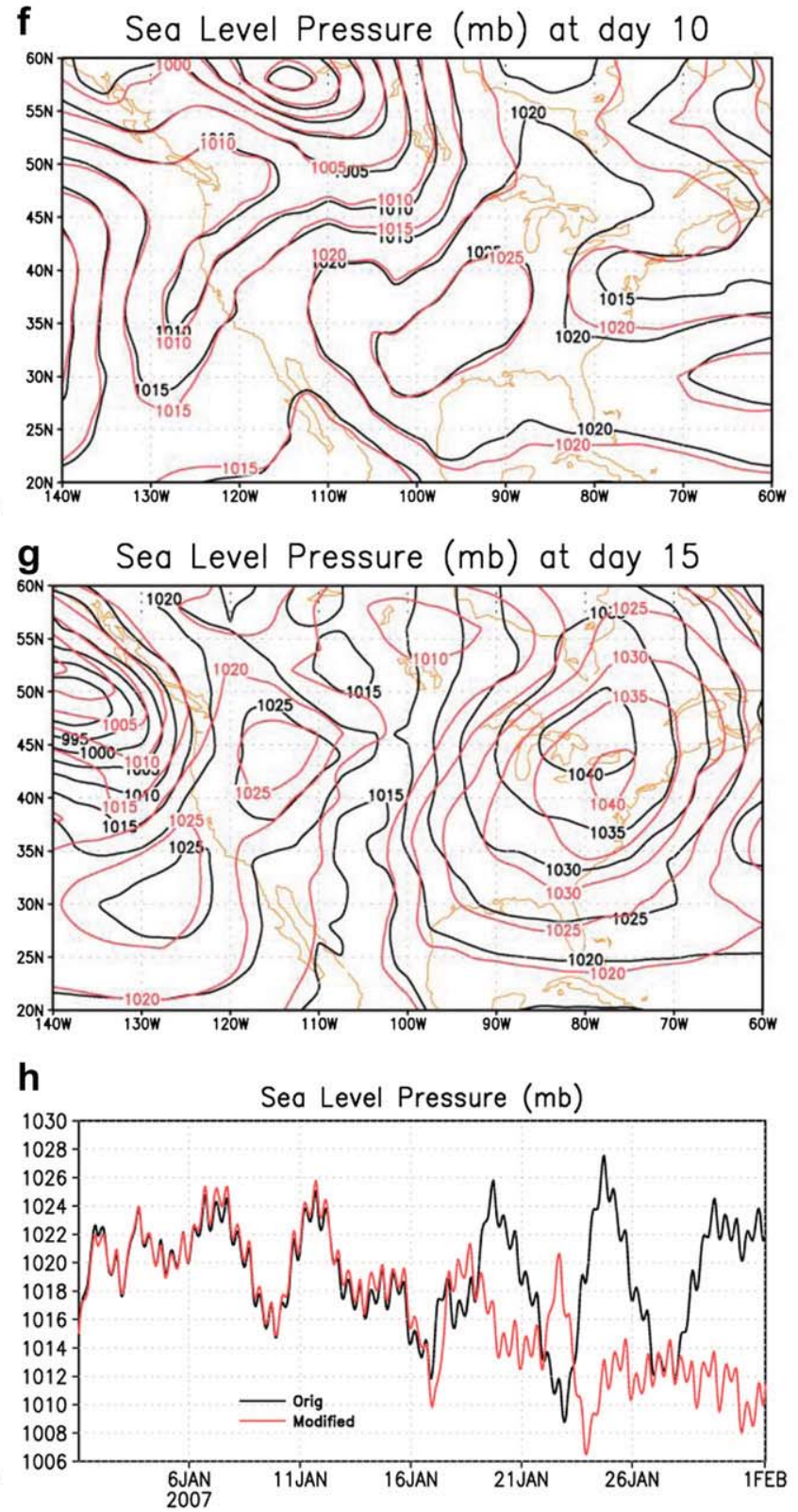

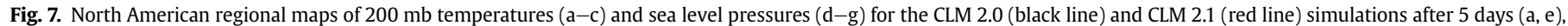

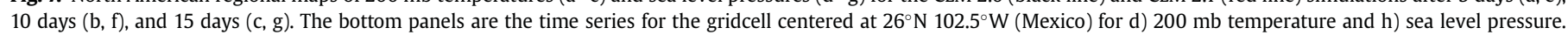


a FLUXNET gridded product, we chose the NASA GMAO reanalysis product, the Modern Era Retrospective-analysis for Research and Applications (MERRA). The MERRA is based on the Goddard Earth Observing System Ver. 5 (GEOS-5, Bosilovich et al., 2006, 2011). The GEOS-5 has the same dynamical core as the GEOS-4 but improved moist process parameterizations and data assimilation (Rienecker et al., 2007). The data assimilation system of GMAO's interactive land-ocean-atmosphere modeling framework is NCEP's Gridpoint Statistical Interpolation (Wu et al., 2002). By comparison, the MMF-LIS results are from free-running simulations, i.e., lacking a data assimilation system, and partially interactive, using observed $\mathrm{SST} /$ sea ice rather than a full-physics ocean model.

Fig. 8 depicts June-August 2007 mean latent heat flux for FLUXNET, MERRA, and the two MMF-LIS simulations. Compared to the FLUXNET and to MMF-LIS, the MERRA map has significantly more latent heat flux over the humid regions of Central Africa, Central to South America, East Asia, Indonesia, and eastern North America. Reichle et al. (2011) attribute this positive bias in areas to excessive interception by dense canopies. The MMF-LIS maps have fewer and smaller areas with latent heat fluxes greater than $120 \mathrm{~W} \mathrm{~m}^{-2}$, although there is a notable hot spot in the extensive wetlands around the Ob River in Central Siberia that is not reflected in the FLUXNET map. In arid Australia and Central Asia, the MERRA performs better than both MMF-LIS simulations. Comparing the different versions of CLM in MMF-LIS, the areas of elevated latent heat flux in Eurasia and North America are smaller and weaker in the modified CLM 2.1. The one area of latent heat flux greater than $120 \mathrm{~W} \mathrm{~m}^{-2}$ in the FLUXNET map is in the Central US. It is better represented in the original CLM 2.0 map, although the modified CLM 2.1 performs better than the CLM 2.0 in the important dry airmass source region in the Mexican high terrain and in the northern tundras affected by the warm bias in CLM 2.0.

\subsection{Precipitation}

There are a number of global gridded precipitation datasets available to assess model performance from diurnal time scales onward. The CMORPH (Climate Prediction Center MORPHing technique) is composed of precipitation estimates derived from low Earth orbiting satellite microwave observations whose features are transported via spatial propagation information obtained from geostationary satellite IR data (Joyce et al., 2004). Fig. 9 contains map views and latitudinal and longitudinal cross sections of CMORPH, MERRA, and the two MMF-LIS simulations of the mean daily precipitation for June-August $2007\left(50^{\circ} \mathrm{N}-50^{\circ} \mathrm{S}\right)$. There are areas where all of the models produce too little precipitation (the equatorial Atlantic, northern Europe, Central US), but there is generally more precipitation in the model output than in the CMORPH. In the Indian-Asian monsoon region, all of the models produce a much larger area of heavy ( $>10 \mathrm{~mm}^{\text {day }}{ }^{-1}$ ) precipitation than in CMORPH. This is particularly acute over the Western Pacific warm pool in the MMF-LIS simulations versus the Indian monsoon region in MERRA. Around Indonesia and in northern South America, Central Asia, and southeastern Australia MERRA is both close to the CMORPH and clearly better than both MMF-LIS simulations. Both MMF-LIS simulations outperform MERRA in sub-Saharan Africa. Over the Pacific, the modified CLM 2.1 outperforms MERRA east and north of the western warm pool. In the latitudinal cross section, the boreal summer rainfall peak is wider in the MERRA, contributing to a global mean rainfall rate $30 \%$ greater than CMORPH versus $23 \%$ greater for MMF-LIS.
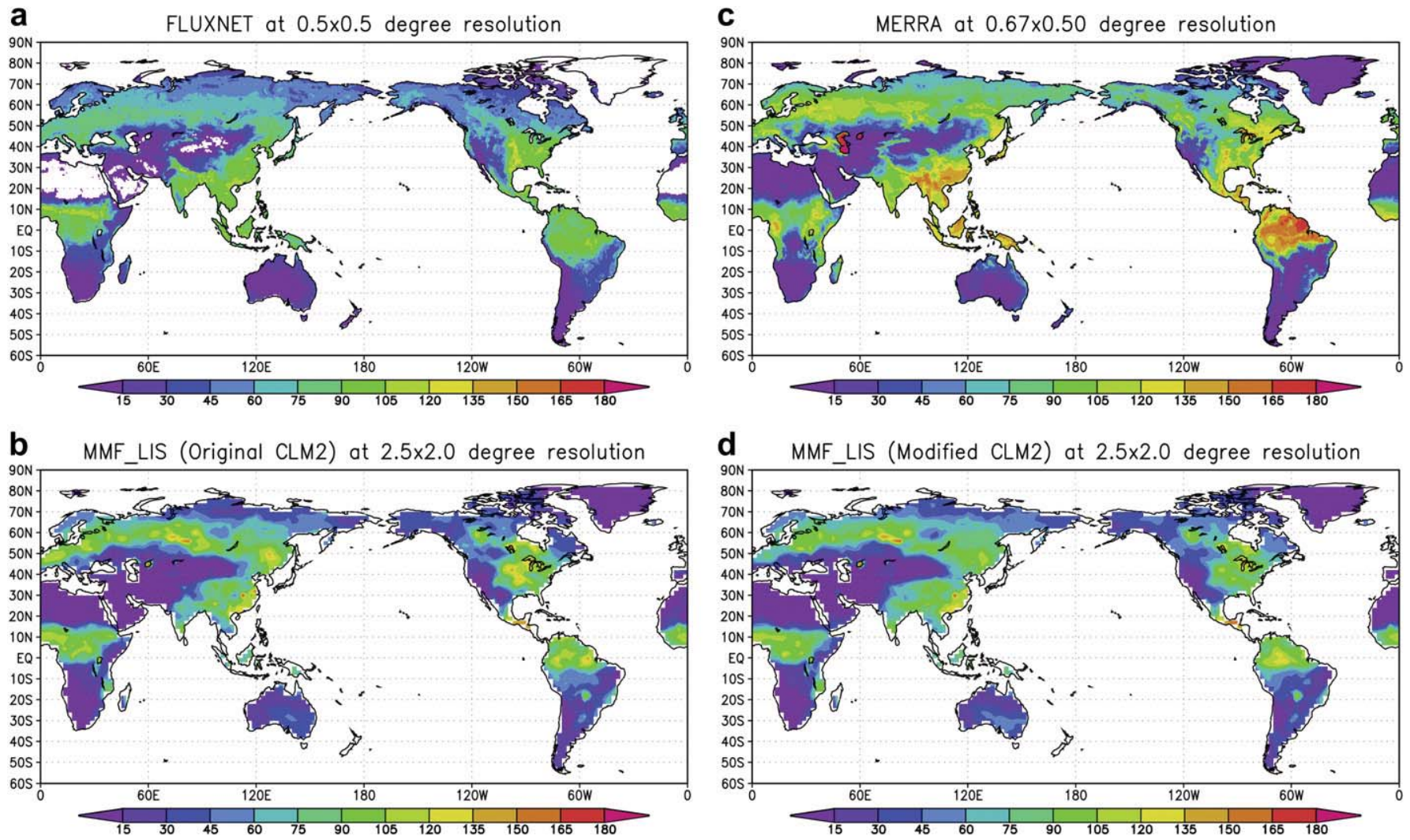

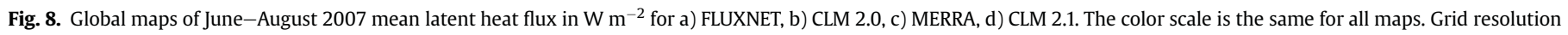
of each map is indicated. 

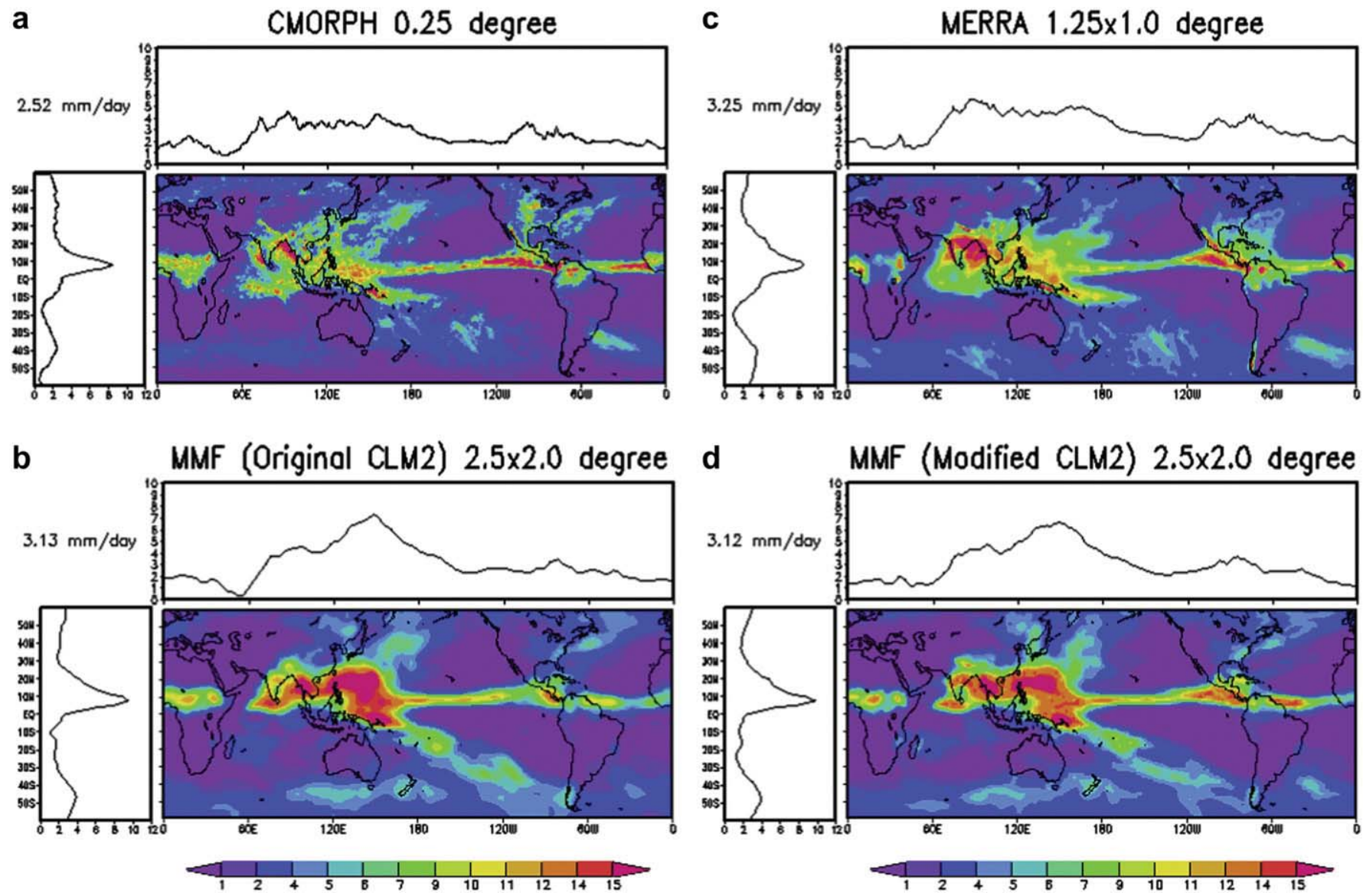

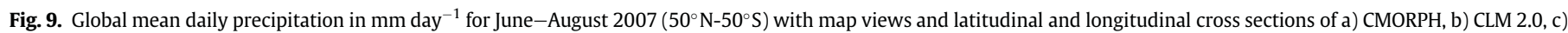
MERRA, d) CLM 2.1.

There are important differences between the MMF-LIS simulations. The modified CLM 2.1 compares better to CMORPH than the original CLM 2.0 in most of the Pacific, the South Atlantic, northeast Asia, the eastern and Central US, and sub-Saharan Africa. The areas affected by the Mexican high terrain source region, the Central US and Mexico, are wetter in the modified CLM 2.1 map. The original CLM 2.0 performs better than the modified CLM 2.1 in a couple much smaller areas, the northwestern Atlantic along the US coast, where CLM 2.1 is too dry, and in southeastern Australia, where CLM 2.1 is too wet. In the South Atlantic, the modified CLM 2.1 has a lower precipitation maximum than MERRA, but it is higher than the original CLM 2.0, and in none of the models is it tangential to the South American coast as in CMORPH. Comparing the longitudinal cross sections, the peak at $150^{\circ} \mathrm{E}$ is lower in the modified CLM 2.1 , contributing to the $1 \%$ reduction in global mean rainfall versus the original CLM 2.0. The results in Fig. 9 for the modified CLM 2.1 are highly similar to the results from the MMF configuration of Tao et al. (2009), completing a successful benchmarking of the MMF-LIS code against the older configuration.

In a study of precipitation biases over the tropical Atlantic by 6 different free-running GCMs by Biasutti et al. (2006), the cumulus parameterizations in the models overestimated the correlation between convective precipitation and surface humidity and underestimated the correlation to upper tropospheric humidity. They were thus acutely sensitive to SST distribution and latent heat flux. This sensitivity is compounded in both parameterized and resolved convection schemes by several additional factors. These schemes produce unrealistically high updraft and downdraft mass fluxes and precipitation efficiencies, raining at column humidities lower than observed, particularly in humid regions (Sui et al., 2007; Kain et al., 2008; Weisman et al., 2008). Unable to sustain high column humidity, they may rain prematurely, affecting the simulation of the diurnal cycle (Mohr et al., 2003; Tompkins and Di Giuseppe, 2003; Bernie et al., 2007) and of convective development associated with fronts and troughs (Zeng et al., 2007; Weisman et al., 2008). The timing and amount of precipitation in simulations with resolved convection is also highly sensitive to the choice of ice microphysical schemes (Li et al., 2009a,b; Satoh et al., 2010) and to the use of cyclic lateral boundary conditions that trap convection within the CRM, producing artificially long lifetimes (Tao et al., 2009).

For coupled ocean-atmosphere model configurations, adjustment between the surface atmospheric and oceanic layers tends to warm surface air temperatures and reduce total cloud amount (Costa et al., 2001; Biasutti et al., 2005; Räisänen et al., 2008). This effect occurs even in slab ocean models, although anomalous latent heat fluxes may develop in slab models to compensate for imposed ocean heat transport, an effect not present in full-physics mixedlayer ocean models (Sutton and Mathieu, 2002). Although the use of mixed-layer ocean models and data assimilation systems can reduce precipitation biases, the results in Figs. 8 and 9 and of previous studies (e.g., Biasutti et al., 2006; Shutts and Palmer, 2007; Stan et al., 2010) suggest improved model physics is still important. Issues with model macro- and microphysics, surface observational networks, satellite radiance retrieval schemes, grid resolution, and the expenses associated with computing and storage remain major issues in global modeling (reviews in Zhang et al., 2005; Guilyardi et al., 2009). 


\section{Conclusions}

\subsection{Summary}

The three principal components of the MMF-LIS are a finitevolume GCM (Goddard Earth Observing System Ver. 4, GEOS-4), a 2D CRM (Goddard Cumulus Ensemble, GCE), and the Land Information System (LIS), representing the large-scale atmospheric circulation, cloud processes, and land surface processes, respectively. This global multi-scale modeling framework exchanges the single-column cumulus parameterization common to conventional GCMs for a 2D CRM running at non-hydrostatic resolutions $(<10-\mathrm{km})$. The MMF-LIS has a horizontal coupling strategy, GCE $\leftrightarrow$ fvGCM $\leftrightarrow$ Coupler $\leftrightarrow$ LIS, that uses an Earth System Modeling Framework Coupler Component to transfer I/O between fvGCM and LIS. This strategy offers significant computational efficiency by simplifying processor distribution during parallel operations and minimizing $\mathrm{I} / \mathrm{O}$ overhead while maximizing its flexibility. The $\mathrm{I} / \mathrm{O}$ between the atmospheric and land surface components can be passed either as fvGCM gridcell means or as cloud-scale (1-10-km) tiles. The latter option permits cloud-scale two-way interaction at a nominal additional computational cost. Coupling with LIS versus a single LSM expands the user's ability to perform ensemble modeling with different LSMs and add and test new model physics.

We tested two different versions of CLM, 2.0 and 2.1, simulating 2007-2008 to assess whether the new MMF-LIS could produce physically realistic results and assess how changes in model physics might affect regional atmospheric dynamics. Our benchmark was the MMF configuration of Tao et al. (2009) that ran CLM 2.1 with simple surface heterogeneity (7 tiles per LIS gridcell). Comparing mean annual global surface temperature maps, large areas of the northern hemisphere were several degrees warmer in the CLM 2.0 simulation. Positive feedbacks between warmer surface, warmer soil, and lower cloud cover set and reinforced the warming tendency, making the positive (original-modified) differences greater in area and magnitude in 2008. By starting each simulation with the same initial conditions, we examined how quickly differences between both simulations would emerge and affect the regional North American circulation. Differences emerged after 2 days for surface temperatures, 5 days for upper tropospheric temperatures, and 10 days for the synoptic-scale surface pressure fields. By the end of the deterministic prediction limit of two weeks, all of the synoptic-scale cyclones and anticyclones in North America had different positions, orientations, and magnitudes.

The first results from MMF-LIS benchmarked successfully against an older configuration of MMF. Examining two MMF-LIS simulations with different LSM physics revealed sensitivity to changes in model physics, producing noteworthy differences in both surface variables and regional circulations. From free-running simulations, the surface fluxes and precipitation over land from MMF-LIS compared well to global gridded observational and reanalysis (MERRA) datasets. The spatial coverage of precipitation greater than $2 \mathrm{~mm}$ day $^{-1}$ from MMF-LIS was comparable to observed. The weakest aspect of the MMF-LIS simulations of global precipitation was the positive precipitation bias in the Indian-Asian monsoon region. Comparing the CLM 2.1 precipitation and latent heat flux maps to the CLM 2.0 simulation and observations showed improvement in many areas, particularly in the northern hemisphere where CLM 2.0 had a notable warm bias.

\subsection{Future directions in global land/atmosphere modeling}

Future improvements in representing land/atmosphere interactions in operational global forecasting models includes improving grid resolutions, better individual physical process representations, and data assimilation, both from better assimilation methodologies and additional data streams (Saha et al., 2010; Bosilovich et al., 2011; Riddaway, 2011; Werth and Garrett, 2011). Adding multi-LSM capability through LIS or a LIS-like interface is not mentioned. Reducing GCM grid resolution will improve the representation of surface heterogeneity by underlying LSMs and thus land/atmosphere interactions. Below $10-\mathrm{km}$, the hydrostatic approximation breaks down, requiring new model formulations in operational agencies that accommodate the potentially opposing requirements of computational speed and physical accuracy while limiting code development time and effort where possible.

At the ECMWF, work is on-going to develop a non-hydrostatic global model that, as computational infrastructure allows, permits the explicit resolution of moist convection with land/ atmosphere interactions at a comparable scale (Yessad and Wedi, 2011). To save development effort, the existing dynamical core of the Météo-France's mesoscale forecasting model Aire Limitée Adaptation Dynamique Développement International (ALADIN) is being evaluated for this role (Bénard et al., 2010). At NCEP, separate operational execution of WRF (with Noah) at 4-km with explicit convection takes place but only over the continental United States and its outlying states and territories (Kain et al., 2008; Carley et al., 2011). Although this area will not be expanded in the near term, a single nested structure is being created from the physical and dynamical cores of NCEP's large-scale Eta and mesoscale WRF models linked by ESMF components and interfaces (Iredell and Black, 2011).

The Goddard MMF-LIS is currently upgrading to GEOS-5. The GEOS-5 is significantly computationally more efficient and will add new functionality to MMF-LIS, in particular, a non-hydrostatic running option, a fully coupled deep-ocean component, and data assimilation capabilities that will allow future utilization of land and atmosphere data assimilation. The latter options will address the positive precipitation biases over the tropical oceans that feedback to the land/atmosphere interaction. The next step conceptually for the present generation of MMF configurations that use zonal arrays of CRMs is described by Arakawa et al. (2011) as a "Quasi-3D MMF" using a network of CRMs forming a grid with large gaps. The gap sizes would be determined by available computational infrastructure and desired application. As computational infrastructure evolves and gaps shrink, a true 3D MMF will emerge.

\section{Acknowledgments}

We are grateful to Drs. H. Maring and D. Anderson at NASA Headquarters (HQ) for their support for developing the MMF under the NASA Cloud Modeling and Analysis Initiative (CMAI) program and to Dr. J. Entin for support for MMF-LIS coupling under the NASA Energy and Water Cycle Science (NEWS) program. We thank Dr. R. Kakar at NASA HQ for his support of GCE development throughout its history. Dr. M. Jung provided the FLUXNET data used in the analysis. We appreciate the effort of our anonymous reviewers to help us improve this manuscript.

\section{References}

Arakawa, A., 2004. The cumulus parameterization problem: past, present, and future. J. Climate 17, 2493-2525.

Arakawa, A., Jung, J.-H., Wu, C.-M., 2011. Toward unification of the multiscale modeling of the atmosphere. Atmos. Chem. Phys. 11, 3731-3742.

Atlas, R., Lin, S.-J., Shen, B.-W., Reale, O., Yeh, K.-S., 2007. Improving hurricane prediction through innovative global modeling. In: Baker, E.K., Joseph, A. Mehrota, A. (Eds.), Extending the Horizons: Advances in Computing, Optimizaton, and Decision Technologies. Springer, pp. 1-14. 
Atlas, R., et al., 2005. Hurricane forecasting with the high-resolution NASA finite volume general circulation model. Geophys. Res. Lett. 32, L03807. doi:10.1029/ 2004 GL021513.

Balaji, V., et al., 2011. ESMF Reference Manual for Fortran Version 5.2, 864 pp. http:// www.earthsystemmodeling.org.

Baldocchi, D., et al., 2001. FLUXNET: a new tool to study the temporal and spatial variability of ecosystem-scale carbon dioxide, water vapor, and energy flux densities. Bull. Amer. Meteor. Soc. 82, 2415-2434.

Balsamo, G., et al., 2009. A revised hydrology for the ECMWF model: verification from field site to terrestrial water storage and impact in the integrated forecast system. J. Hydrometeor. 10, 623-643.

Bénard, P., et al., 2010. Dynamical kernel of the Aladin-NH spectral limited-area model: revised formulation and sensitivity experiments. Quart. J. Roy. Meteor. Soc. 136, 155-169.

Benedict, J.J., Randall, D.A., 2009. Structure of the Madden-Julian oscillation in the superparameterized CAM. J. Atmos. Sci. 66, 3277-3296.

Benjamin, S.G., 1986. Some effects of surface heating and topography on the regional severe storm environment. Part II: two-dimensional idealized experiments. Mon. Wea. Rev. 114, 307-329.

Bernie, D.J., Guilyardi, E., Madec, G., Slingo, J.M., Woolnough, S.J., 2007. Impact of resolving the diurnal cycle in an ocean-atmosphere GCM. Part 1: a diurnally forced OGCM. Clim. Dyn. 29, 575-590.

Biasutti, M., Battisti, D.S., Sarachik, E.S., 2005. Terrestrial influence on the annual cycle of the Atlantic ITCZ in an AGCM coupled to a slab ocean model. J. Climate $18,211-228$.

Biasutti, M., Sobel, A.H., Kushnir, Y., 2006. AGCM precipitation biases in the Tropical Atlantic. J. Climate 19, 935-958.

Blossey, P.N., Bretherton, C.S., Wyant, M.C., 2009. . Subtropical low cloud response to a warmer climate in a superparameterized climate model. Part II: column modeling with a cloud resolving model. J. Adv. Model. Earth Syst. 1. doi:10.3894/JAMES.2009.1.8.

Blyth, E., et al., 2010. Evaluating the JULES land surface model energy fluxes using FLUXNET data. J. Hydrometeor. 11, 509-519.

Bosilovich, M.G., Robertson, F.R., Chen, J., 2011. Global energy and water budgets in MERRA. J. Climate 24, 5721-5739.

Bosilovich, M.G., et al., 2006. NASA's modern era retrospective-analysis for research and applications (MERRA). U.S. CLIVAR Variations 4, 5-8.

Carley, J.R., et al., 2011. A proposed model-based methodology for feature-specific prediction for high-impact weather. Wea. Forecasting 26, 243-249.

Collins, N., et al., 2005. Design and implementation of components in the earth system modeling framework. Int. J. High Perform. Comput. Appl. 19, 341-350.

Collins, W.D., et al., 2006. The Community Climate System Model Version 3 (CCSM3). J. Climate 19, 2122-2143.

Costa, A.A., Cotton, W.R., Walko, R.L., Pielke, R.A., 2001. Coupled ocean-cloudresolving simulations of the air-sea interaction over the equatorial Western Pacific. J. Atmos. Sci. 58, 3357-3375.

Dai, Y., et al., 2003. The common land model. Bull. Amer. Meteor. Soc. 84, 1013-1023.

DeMott, C.A., Randall, D.A., Khairoutdinov, M., 2007. Convective precipitation variability as a tool for general circulation model analysis. J. Climate 20, 91-112.

Ek, M.B., et al., 2003. Implementation of Noah land surface model advances in the National Centers for Environmental Prediction operational mesoscale Eta model. J. Geophys. Res. 108, 8851.

Grabowski, W.W., 2001. Coupling cloud processes with the large-scale dynamics using the Cloud-Resolving Convection Parameterization (CRCP). J. Atmos. Sci. 58, 978-997.

Guilyardi, E., et al., 2009. Understanding El Niño in ocean-atmosphere general circulation models: progress and challenges. Bull. Amer. Meteor. Soc. 90, $325-340$.

Hill, C., DeLuca, C., Balaji, V., Suarez, M., da Silva, A., 2004. The architecture of the earth system modeling framework. Comput. Sci. Eng. 6, 18-28.

Iredell, M., Black, T., January 2011. The NOAA Environmental Modeling System at NCEP, 20th Conference on Numerical Weather Prediction. American Meteorological Society, Los Angeles, CA, 23-28 pp.

Joyce, R.J., Janowiak, J.E., Arkin, P.A., Xie, P., 2004. CMORPH: a method that produces global precipitation estimates from passive microwave and infrared data at high spatial and temporal resolution. J. Hydrometeor. 5, 487-503.

Jung, M., Reichstein, M., Bondeau, A., 2009. Towards global empirical upscaling of FLUXNET eddy covariance observations: validation of a model tree ensemble approach using a biosphere model. Biogeosciences 6, 2001-2013.

Jung, M., et al., 2010. Recent decline in the global land evaportranspiration trend due to limited moisture supply. Nature 467, 951-954. doi:10.1038/ nature09396.

Kain, J.S., et al., 2008. Some practical considerations regarding horizontal resolution in the first generation of operational convection-allowing NWP. Wea. Forecasting 23, 931-952.

Kanamitsu, M., et al., 2002. NCEP-DOE AMIP-II reanalysis (R-2). Bull. Amer. Meteor. Soc. $83,1631-1643$.

Khairoutdinov, M., DeMott, C., Randall, D., 2008. Evaluation of the simulated interannual and subseasonal variability in an AMIP-style simulation using the CSU Multiscale Modeling Framework. J. Climate 21, 413-431.

Khairoutdinov, M.F., Randall, D.A., 2001. A cloud resolving model as a cloud parameterization in the NCAR community climate system model: preliminary results. Geophys. Res. Lett. 28, 3617-3620.
Khairoutdinov, M.F., Randall, D.A., 2003. Cloud resolving modeling of the ARM summer 1997 IOP: model formulation, results, uncertainties, and sensitivities. J. Atmos. Sci. 60, 607-625.

Kiehl, J.T., et al., 1998. The National Center for Atmospheric Research Community Climate Model: CCM3. J. Climate 11, 1131-1149.

Koster, R.D., Suarez, M.J., Ducharne, A., Stieglitz, M., Kumar, P., 2000. A catchmentbased approach to modeling land surface processes in a general circulation model. 1. Model structure. J. Geophys. Res. 105, 24809-24822.

Kumar, S.V., Peters-Lidard, C.D., Eastman, J.L., Tao, W.-K., 2008. An integrated highresolution hydrometeorological modeling testbed using LIS and WRF. Environ. Model. Software 23, 169-181.

Kumar, S.V., et al., 2006. Land Information System - An interoperable framework for high resolution land surface modeling. Environ. Model. Software 21, $1402-1415$

Lakhtakia, M.N., Warner, T.T., 1987. A real-data numerical study of the development of precipitation along the edge of an elevated mixed layer. Mon. Wea. Rev. 115, $156-168$

Lang, S., et al., 2007. Improving simulations of convective systems from TRMM LBA: easterly and westerly regimes. J. Atmos. Sci. 64, 1141-1164.

Lang, S., Tao, W.-K., Zeng, X., Li, Y., 2011. Reducing the biases in simulated radar reflectivities from a bulk microphysics scheme: tropical convective systems. J. Atmos. Sci. 68, 2306-2320.

Lanicci, J.M., Carlson, T.N., Warner, T.T., 1987. Sensitivity of the Great Plains severe-storm environment to soil-moisture distribution. Mon. Wea. Rev. 115 2660-2673.

Lewis, J.M., 2005. Roots of ensemble forecasting. Mon. Wea. Rev. 133, 1865-1885

Li, X., Tao, W.-K., Khain, A., Simpson, J., Johnson, D., 2009a. Sensitivity of a cloudresolving model to bulk and explicit-bin microphysics schemes: Part I: comparisons. J. Atmos. Sci. 66, 3-21.

Li, X., Tao, W.-K., Khain, A., Simpson, J., Johnson, D., 2009b. Sensitivity of a cloudresolving model to bulk and explicit-bin microphysics schemes: Part II: cloud microphysics and storm dynamics interactions. J. Atmos. Sci. 66, 22-40.

Lin, S.-J., 1998. Reply to comments by T. Janjić on 'A finite-volume integration method for computing pressure gradient force in general vertical coordinates' (July B, 1997, 123, 1749-1762). Quart. J. Roy. Meteor. Soc. 124, 2531-2533.

Lin, S.-J., 2004. A "vertically Lagrangian" finite-volume dynamical core for global models. Mon. Wea. Rev. 132, 2293-2307.

Lin, S.-J., Rood, R.B., 1996. Multidimensional flux-form semi-Lagrangian transport schemes. Mon. Wea. Rev. 124, 2046-2070.

Lin, S.-J., Rood, R.B., 1997. An explicit flux-form semi-Lagrangian shallow-water model on the sphere. Quart. J. Roy. Meteor. Soc. 123, 2477-2498.

Mohr, K.I., Baker, R.D., Tao, W.-K., Famiglietti, J.S., 2003. The sensitivity of West African convective line water budgets to land cover. J. Hydrometeor. 4, 62-76.

Moncrieff, M.W., Krueger, S.K., Gregory, D., Redelsperger, J.-L., Tao, W.-K., 1997. GEWEX Cloud System Study (GCSS) working group 4: precipitating convective cloud systems. Bull. Amer. Meteor. Soc. 78, 831-845.

Pauluis, O., Garner, S., 2006. Sensitivity of radiative-convective equilibrium simulations to horizontal resolution. J. Atmos. Sci. 63, 1910-1923.

Peters-Lidard, C.D., et al., 2007. High-performance earth system modeling with NASA/GSFC's Land Information System. Inn. Sys. Soft. Eng. 3, 157-165.

Pielke Sr., R.A., 2001. Influence of the spatial distribution of vegetation and soils on the prediction of cumulus convective rainfall. Rev. Geophys. 39, 151-177.

Pritchard, M.S., Moncrieff, M.W., Somerville, R.C.J., 2011. Orogenic propagating precipitation systems over the United States in a global climate model with embedded explicit convection. J. Atmos. Sci. 68, 1821-1840.

Räisänen, P., Järvenoja, S., Järvinen, H., 2008. Noise due to the Monte Carlo independent-column approximation: short-term and long-term impacts in ECHAM5. Quart. J. Roy. Meteor. Soc. 134, 481-495.

Randall, D., Khairoutdinov, M., Arakawa, A., Grabowski, W., 2003a. Breaking the cloud parameterization deadlock. Bull. Amer. Meteor. Soc. 84, 1547-1564.

Randall, D., et al., 2003b. Confronting models with data: the GEWEX Cloud Systems Study. Bull. Amer. Meteor. Soc. 84, 455-469.

Reichle, R.H., et al., 2011. Assessment and enhancement of MERRA land surface hydrology estimates. J. Climate. 24, 6322-6338.

Reynolds, R.W., Rayner, N.A., Smith, T.M., Stokes, D.C., Wang, W., 2002. An improved in situ and satellite SST analysis for climate. J. Climate 15, 1609-1625.

Riddaway, R. (Ed.), 2011. Data Assimilation for Atmosphere and Ocean. ECMWF Newsletter, Spring 2011, vol. 127, 34 pp.

Rienecker, M.M., et al., 2007. The GEOS-5 Data Assimilation System-Documentation of Versions 5.0.1 and 5.1.0. In: NASA/TM-2007-104606, vol. 27, $92 \mathrm{pp}$.

Saha, S., et al., 2010. The NCEP climate forecast system reanalysis. Bull. Amer Meteor. Soc. 91, 1015-1057.

Satoh, M., Inoue, T., Miura, H., 2010. Evaluations of cloud properties of global and local cloud system resolving models using CALIPSO and CloudSat simulators. J. Geophys. Res. 115, D00H14. doi:10.1029/2009JD012247.

Schlosser, C.A., Gao, X., 2010. Assessing evapotranspiration estimates from the second Global Soil Wetness Project (GSWP-2) simulations. J. Hydrometeor. 11, 880-897.

Shen, B.W., et al., 2006a. The 0.125 degree finite-volume general circulation model on the NASA Columbia supercomputer: preliminary simulations of mesoscale vortices. Geophys. Res. Lett. 33, L05801. doi:10.1029/2005GL024594.

Shen, B.W., et al., 2006b. . Hurricane forecasts with a global mesoscale-resolving model: preliminary results with Hurricane Katrina (2005). Geophys. Res. Lett. 33, L13813. doi:10.1029/2006GL026143. 
Shen, B.W., Tao, W.K., Lau, W.K., Atlas, R., 2010. . Predicting tropical cyclogenesis with a global mesoscale model: hierarchical multiscale interactions during the formation of tropical cyclone Nargis (2008). J. Geophys. Res. 115, D14102. doi:10.1029/2009JD013140.

Shutts, G.J., Palmer, T.N., 2007. Convective forcing fluctuations in a cloud-resolving model: relevance to the stochastic parameterization problem. J. Climate 20 187-202.

Stan, C., et al., 2010. An ocean-atmosphere climate simulation with an embedded cloud resolving model. Geophys. Res. Lett. 37, L01702. doi:10.1029/ 2009GL040822.

Sui, C.-H., Li, X., Yang, M.-J., 2007. On the definition of precipitation efficiency. J. Atmos. Sci. 64, 4506-4513.

Sutton, R., Mathieu, P.P., 2002. Response of the atmosphere-ocean mixed-laye system to anomalous ocean heat-flux convergence. Quart. J. Roy. Meteor. Soc. $128,1259-1275$

Tao, W.-K., 2003. Goddard Cumulus Ensemble (GCE) model: application for understanding precipitation processes. Meteorological Monographs 29, 107-138.

Tao, W.-K., et al., 2009. A multiscale modeling system: developments, applications, and critical issues. Bull. Amer. Meteor. Soc. 90, 515-534.

Tao, W.-K., Simpson, J., 1993. Goddard Cumulus Ensemble model. Part I: description. Terr. Atmos. Oceanic Sci. 4, 35-72.

Tao, W.-K., et al., 2003. Microphysics, radiation and surface processes in a nonhydrostatic model. Meteor. Atmos. Phys. 82, 97-137.

Tompkins, A.M., Di Giuseppe, F., 2003. Solar radiative biases in deep convective regimes: possible implications for dynamical feedback. Quart. J. Roy. Meteor Soc. $129,1721-1730$.

Trier, S.B., LeMone, M.A., Chen, F., Manning, K.W., 2011. Effects of surface heat and moisture exchange on ARW-WRF warm-season precipitation forecasts over the Central United States. Wea. Forecasting 26, 3-25.

Wang, M., et al., 2011a. The multi-scale aerosol-climate model PNNL-MMF: mode description and evaluation. Geosci. Model Dev. 4, 137-168.
Wang, M., et al., 2011b. Aerosol indirect effects in a multi-scale aerosol-climate model PNNL-MMF. Atmos. Chem. Phys. 11, 5431-5455.

Weisman, M.L., Davis, C., Wang, W., Manning, K.W., Klemp, J.B., 2008. Experiences with $0-36$-h explicit convective forecasts with the WRF-ARW model. Wea. Forecasting 23, 407-437.

Werth, D., Garrett, A., 2011. Patterns of land surface errors and biases in the global forecast system. Mon. Wea. Rev. 139, 1569-1582.

Wu, W.-S., Purser, R.J., Parrish, D.F., 2002. Three-dimensional variational analysis with spatially inhomogeneous covariances. Mon. Wea. Rev. 130, 2905-2916.

Yessad, K., Wedi, N.P., 2011. The Hydrostatic and Nonhydrostatic Global Model IFS ARPEGE: Deep-layer Model Formulation and Testing, ECMWF Technical Memoranda 657. European Centre for Medium-Range Weather Forecasts, Reading U.K, 26 pp.

Yoden, S., 2007. Atmospheric predictability. J. Meteor. Soc. Japan 85B, 77-102.

Zeng, X., et al., 2005. Treatment of undercanopy turbulence in land models. J. Climate 18, 5086-5094.

Zeng, X., et al., 2008. On the sensitivity of atmospheric ensemble to cloud microphysics in long-term cloud-resolving model simulations. J. Meteor. Soc. Japan 86, 839-856.

Zeng, X., et al., 2009. A contribution by ice nuclei to global warming. Quart. J. Roy. Meteor. Soc. 136, 1614-1629.

Zeng, X., et al., 2007. Evaluation of long-term cloud-resolving modeling with observational cloud data. J. Atmos. Sci. 64, 4153-4177.

Zhang, M., Klein, S., Randall, D., Cederwall, R., Genio, A.D., 2005. Introduction to special section on toward teducing cloud-climate uncertainties in atmospheric general circulation models. J. Geophys. Res. 110, D15S01. doi:10.1029/ 2005JD005923.

Ziemke, J.R., Chandra, S., Bhartia, P.K., 1998. Two new methods for deriving tropospheric column ozone from TOMS measurements: assimilated UARS MLS HALOE and convective-cloud differential techniques. J. Geophys. Res. 103 22115-22127. 